\title{
Successful use of recombinant activated factor VII for postoperative associated haemorrhage: a case report
}

Konstantinos Vlachos, ${ }^{4}$, Fotis Archontovasilis ${ }^{3}$, Artemisia Papadima ${ }^{3}$, Dimitrios Maragiannis ${ }^{1}$, Stavros Aloizos ${ }^{2}$, Emmanuel Lagoudianakis*3, Ioannis G Dalianoudis ${ }^{5}$, Nikolaos Koronakis ${ }^{5}$, John Chrysikos ${ }^{5}$, Spyros Zaravinos ${ }^{4}$ and Andreas Manouras ${ }^{3}$

\author{
Address: ${ }^{1} 1$ st Department of Internal Medicine, 401 General Army Hospital of Athens, Athens, Greece, ${ }^{2}$ Intensive Care Unit, 401 General Army \\ Hospital of Athens, Athens, Greece, ${ }^{3} 1$ st Department of Propedeutic Surgery, Hippokrateio General Hospital, University of Athens, Athens, Greece, \\ ${ }^{4} 1$ st Surgical Department, 401 General Army Hospital of Athens, Athens, Greece and 52st Department of Surgery, 417 NIMTS, Athens, Greece \\ Email: Konstantinos Vlachos - red_threat2000@hotmail.com; Fotis Archontovasilis - akotzadi@yahoo.gr; \\ Artemisia Papadima - emlag@med.uoa.gr; Dimitrios Maragiannis - rederdine@yahoo.gr; Stavros Aloizos - awace1@yahoo.gr; \\ Emmanuel Lagoudianakis* - redemlag@yahoo.gr; Ioannis G Dalianoudis - johndalas@gmail.com; \\ Nikolaos Koronakis - nkoronakis@ath.forthnet.gr; John Chrysikos - johngold@otenet.gr; Spyros Zaravinos - adminf@pathfinder.gr; \\ Andreas Manouras - amanouras@hippocratio.gr \\ * Corresponding author
}

Published: 29 November 2008

Cases Journal 2008, I:36I doi:10.1186/1757-|626-I-36I

This article is available from: http://www.casesjournal.com/content/I/I/36I

(C) 2008 Vlachos et al; licensee BioMed Central Ltd.

This is an Open Access article distributed under the terms of the Creative Commons Attribution License (http://creativecommons.org/licenses/by/2.0), which permits unrestricted use, distribution, and reproduction in any medium, provided the original work is properly cited.

\begin{abstract}
Background: Coagulopathy is a major contributing factor to bleeding related mortality even after achieving adequate surgical control of the haemorrhage in trauma and surgical patients.

Case presentation: A 65 years old Greek man was admitted in our ICU with critical haemorrhage following renal biopsy. Despite surgical exploration the patient continued to bleed resulting in a vicious cycle of transfusion, coagulopathy and re-bleeding. After all standard management options were exhausted, the patient was given rFVIla (total dose 4,8 $\mathrm{mg}$ ). Clinical improvement was noted without adverse thrombotic complications. One month later the same patient was operated on for a suspected retroperitoneal infected collection that it was assumed to be the cause of persistent pyrexia. After abdominal washout, he suffered haemorrhagic shock with postoperative coagulopathy. Standard transfusion therapy was again unsuccessful. The patient was given rFVlla again resulting in an immediate reduction in coagulopathic haemorrhage accompanied by a significant improvement in laboratory measurements and reduction in blood products requirements.
\end{abstract}

Conclusion: Published clinical experiences for the use of rFVIla in trauma patients are limited to small series and case reports. However, in trauma patients, administration of rFVlla appears to be effective in addition to prompt surgical intervention as an adjunctive haemostatic measure to control life threatening bleeding in appropriately selected patients. 


\section{Background}

Coagulopathy is a major contributing factor to bleeding related mortality even after achieving adequate surgical control of the haemorrhage in trauma and surgical patients, particularly when associated with metabolic acidosis and hypothermia $[1,2]$.

Recombinant activated factor VII(rFVIIa) has been approved since nearly a decade for the prevention and treatment of bleeding episodes in haemophilic patients with inhibitors to coagulation factor VII or factor IX [3]. Recent studies reports the successful management of massive obstetric haemorrhage with the use of rFVIIa[4]. However, administration of rFVIIa appears to be effective in addition to prompt surgical intervention as an adjunctive haemostatic measure to control life threatening bleeding in trauma patients as well as postoperative haemorrhage. Furthermore, recent case reports [5-7] and case series II [1,8-12], have also suggested a role of rFVIIa in the management of life threatening bleeding in patients with trauma induced coagulopathies who do not respond to conventional treatments.

We describe the successful use of rFVIIa in the management of a patient with no pre-existing coagulopathy who developed refractory bleeding following renal biopsy, for persistent proteinuria $(2,5 \mathrm{gr} /$ day $)$, despite adequate therapy.

\section{Case presentation}

A 65 year old Greek man with unremarkable previous medical history, was admitted to our ICU because of haemorrhage after renal biopsy. On admission, examination revealed a respiratory rate of $30 / \mathrm{min}$, a pulse rate of $138 / \mathrm{min}$ and a blood pressure of 79/58 $\mathrm{mmHg}$. He was in a critical condition with profound hypovolaemic shock, acute renal failure and coagulopathy. Despite volume resuscitation and transfusion of 8 units of Red Blood Cells (RBC) and 4 units of Fresh Frozen Plasma (FFP) the patient developed a rapidly expanding abdomen. He was transported immediately to the operating room for laparotomy.
His preoperative airway examination was unremarkable: mouth opening, oropharyngeal view, thyromental distance, and neck movement were all normal. For anaesthetic induction, after three minutes of pre-oxygenation with $100 \% \mathrm{O}_{2}$ and initiation of cricoid pressure, the patient received midazolam $2 \mathrm{mg}$ iv, fentanyl $100 \mathrm{mcg}$ iv, etomidate $16 \mathrm{mg}$ iv, and succinylcholine $80 \mathrm{mg}$ iv.

Anaesthesia was maintained with sevoflurane (MAC 1$1.2)$ in air and oxygen $\left(\mathrm{FiO}_{2} 50 \%\right)$, and intermittent boluses of fentanyl and rocuronium. The standard monitoring included ECG, capnometry, invasive measurement of blood pressure and central venous pressure, pulsoximetry, diuresis, esophageal and tympanic temperature. Bispectral analysis of the electroencephalogram was used as a guide for anaesthetic depth and bispectral index levels were maintained between 40 and 55. Ligation of the bleeding left kidney vessels was accomplished.

After completion of the operation mechanical ventilation was continued in ICU. Four hours later the patient became haemodynamically unstable with a rapid drop of his haematocrit, while he required increased doses of fluids and vasopressors. A 4-lumen central venous catheter and a pulmonary artery catheter were inserted via puncture of the internal jugular vein. In addition, 4 units of RBC, 13 units of FFP and 6 units of platelets were administered. His status did not stabilise and he was taken directly to the operating room where bleeding from splenic vessels was found. The same philosophy of anaesthetic management is being applied to the perioperative period. Emergency splenectomy was carried out. As his condition further deteriorated administration of rFVIIa, as last effort to control his bleeding, was decided. A total dose of $4,8 \mathrm{mg}(60 \mu \mathrm{g} / \mathrm{kg})$ of rFVIIa along with concurrent transfusion of 4 units of FFP, 2 units of RBC and 6 units of platelets were given. Remarkably, all signs of bleeding appeared to cease (Table 1), the patient's haemodynamic parameters also stabilised and his tissue perfusion and metabolic acidosis gradually improved. There were no further episodes of recurrent haemorrhage. On the second postoperative day, his trachea was extubated in the oper-

Table I: Compering charts of haemodynamic parameters after the use of rFVIla for the Ist time

\begin{tabular}{ccc}
\hline & Before the use of rFVIla (4,8 $\mathbf{~ m g})$ & After the use of rFVIIa (4,8 $\mathbf{~ m g})$ \\
\hline PT & 24,1 & 14,1 \\
\hline aPTT & 54,7 & 47,7 \\
\hline INR & 2,15 & 1,24 \\
\hline
\end{tabular}

PT: Prothrombin Time aPTT: Partial Prothrombin Time INR: International Normalisation Ratio 
ating room and thereafter he was discharged home on postoperative day 6 .

One month later the patient was operated on for a suspected retroperitoneal infected collection that it was assumed to be the cause of persistent pyrexia. After abdominal washout he suffered another episode of severe intraabdominal bleeding with postoperative coagulopathy. Despite the transfusion of 30 units of FFP, 18 units of RBC and 6 units of platelets to control his bleeding, no substantial benefit was observed. We, thereafter, decided to administer again $12 \mathrm{mg}(150 \mu \mathrm{g} / \mathrm{kg})$ of rFVIIa within 16 hours, which resulted in cessation of bleeding shortly after the last dose of rFVIIa with no recurrent episodes of haemorrhage, and correction of clotting parameters (Table 2).

\section{Discussion}

The mechanism of coagulopathy in trauma is complex and multi factorial. It includes dilutional coagulopathy, hypothermia, acidosis, hyperfibrinolysis, anaemia and extensive consumption of platelets and coagulation factors $[13,14]$.

Administration of high doses of rFVIIa results in a huge increase of rFVIIa compared with the physiologic state, leading to faster and higher thrombin generation [9]. The recently developed cell base model of coagulation suggests that rFVIIa enhances haemostasis at the site of injury without systemic hypercoagulable effect [13]. In our report we used doses $4,8 \mathrm{mg}(60 \mu \mathrm{g} / \mathrm{kg})$ and $12 \mathrm{mg}(150$ $\mu \mathrm{g} / \mathrm{kg}$ ) of rFVIIa respectively. Because widely different doses have been used in the published reports, the optimal dosing regimen for rFVIIa has not yet been established.

Our observation regarding the apparent efficacy of rFVIIa is consistent with a growing body of evidence suggesting a role of rFVIIa for the management of bleeding in surgical patients $[1,4,6,9-11,15]$. Complete correction of the INR, shortening of the PT and marked improvement of aPTT was achieved after treatment with rFVIIa in our patient. However, normalisation of laboratory measurements of coagulation, in particular the PT, is rather artificial and does not appear to reflect correction of in vivo coagulation [15].

Previous clinical experience with rFVIIa supports a good safety profile. More than 6500 patients have received rFVIIa and only 17 adverse events have been reported. In the reviewed, $4 \%$ thromboembolic events were noted, of which $1 \%$ occurred in trauma patients[10]. In another study less that $0,05 \%$ of serious thromboembolic events occurred in 400.000 doses[13]. In our patient there was no clinical evidence of thromboembolic events.

Its relative high cost would be offset by the costs that would otherwise occur after additional blood transfusions, surgical interventions, shock and other adverse events associated with haemorrhage. We should also consider the benefits of reduced immunologic and viral load, and the decreased implication of organ system failure related to increased transfusion volume.

\section{Conclusion}

Although investigational use of rFVIIa in trauma patients has shown promising results, the data supporting the use of rFVIIa within trauma have been limited to case series and anecdotal reports. However, in appropriately selected trauma patients rFVIIa may play a role as an adjunctive haemostatic measure in addition to surgical haemostasis.

\section{Abbreviations}

ICU: Intensive Care Unit; rFVIIa: recombinant activated Factor VII; RBC: Red Blood Cells; FFP: Fresh Frozen Plasma; $\mathrm{O}_{2}$ : Oxygen; MAC: Minimal Alveolar Concentration; ECG: Electrocardiogram; INR: International Normalisation Ratio; PT: Prothrombin Time; aPTT: Partial Prothrombin Time

\section{Consent}

Written informed consent was obtained from the patient for publication of this case report and any accompanying images. A copy of the written consent is available for review by the Editor-in-Chief of this journal.

Table 2: Compering charts of clotting parameters after the use of rFVIla for the $2^{\text {nd }}$ time

\begin{tabular}{ccc}
\hline & Before the use of rFVIIa (I $\mathbf{~ m g})$ & After the use of rFVIIa (I2 mg) \\
\hline PT & 16,4 & 11,7 \\
\hline aPTT & 148,4 & 40,7 \\
\hline INR & 1,44 & 0,99 \\
\hline
\end{tabular}

PT: Prothrombin Time aPTT: Partial Prothrombin Time INR: International Normalisation Ratio 


\section{Competing interests}

The authors declare that they have no competing interests.

\section{Authors' contributions}

$\mathrm{KV}$ assisted in the operation contributed to manuscript conception, research, acquisition of data, drafting and writing of the manuscript. FT contributed to manuscript conception, research, acquisition of data, drafting and writing of the manuscript. AP contributed to manuscript conception, research, acquisition of data, drafting and writing of the manuscript. DM contributed to manuscript conception, research, acquisition of data, drafting and writing of the manuscript. SA contributed to manuscript conception, research, acquisition of data, drafting and writing of the manuscript. EL contributed to organizing, drafting and critical review of the manuscript. IGD contributed to organizing, drafting and critical review of the manuscript. NK contributed to organizing and drafting of the manuscript, and critically revised the manuscript. JC contributed to organizing and drafting of the manuscript, and critically revised the manuscript. SZ assisted in the operation and contributed to critical review of the manuscript. AM contributed to manuscript conception, research, acquisition of data, drafting and writing of the manuscript. All authors read and approved the final manuscript.

\section{References}

I. Dutton RP, McCunn M, Hyder M, D'Angelo M, O'Connor J, Hess JR, Scalea TM: Factor VIla for correction of traumatic coagulopathy. J Trauma 2004, 57:709-7I9.

2. Hoyt DB, Bulger EM, Knudson MM, Morris J, lerardi R, Sugerman HJ, Shackford SR, Landercasper J, Winchell RJ, Jurkovich G, et al.: Death in the operating room: an analysis of a multi-center experience. I Trauma 1994, 37:426-432.

3. Food and Drug Administration, US: License No.126I issued in accordance with the provisions of Section 351 (a) of the Public Health Service Act, as amended November 21, 1997 CFDAMA; Public Law I 05-I I 5. J Approval letter. March 25, 1999; reference no 96-0597

4. Bhuskute N, Kritzinger S, Dakin M: Recombinant factor VIla in massive obstetric haemorrhage. Eur J Anaesthesiol 2008, 25:250-25I.

5. Vlot AJ, Ton E, Mackaay AJ, Kramer MH, Gaillard CA: Treatment of a severely bleeding patient without preexisting coagulopathy with activated recombinant factor VII. Am J Med 2000, 1 08:421-423.

6. O'Neill PA, Bluth M, Gloster ES, Wali D, Priovolos S, DiMaio TM, Essex DW, Catanese CA, Strauss RA: Successful use of recombinant activated factor VII for trauma-associated hemorrhage in a patient without preexisting coagulopathy. J Trauma 2002, 52:400-405.

7. Kenet G, Walden R, Eldad A, Martinowitz U: Treatment of traumatic bleeding with recombinant factor VIla. Lancet 1999, 354:1879-1879.

8. Boffard KD, Riou B, Warren B, Choong PI, Rizoli S, Rossaint R, Axelsen M, Kluger Y, NovoSeven Trauma Study Group: Recombinant factor VIla as adjunctive therapy for bleeding control in severely injured trauma patients: two parallel randomized, placebo-controlled, double-blind clinical trials. J Trauma 2005, 59(I): I5-18.

9. Martinowitz U, Kenet G, Segal E, Luboshitz J, Lubetsky A, Ingerslev J, Lynn M: Recombinant activated factor VII for adjuctive hemorrhage control in trauma. J Trauma 200I, 5 I:431-439.
10. Barletta JF, Ahrens CL, Tyburski JG, Wilson RF: A review of recombinant factor VII for refractory bleeding in nonhemophilic trauma patients. J Trauma 2005, 58:646-65I.

II. Khan AZ, Parry JM, Crowley WF, McAllen K, Davis AT, Bonnell BW Hoogeboom JE: Recombinant factor VIla for the treatment of severe postoperative and traumatic hemorrhage. Am J Surg 2005, | 89:33|-334.

12. Aggarwal A, Malkovska V, Catlett JP, Alcorn K: Recombinant activated VII (rFVIla) as salvage treatment for intractable hemorrhage. Thromb J 2004, 2:9.

13. Martinowitz U, Michaelson M, The Israeli Multidisciplinary rFVIla Task Force: Guidelines for the use of recombinant activated factor VII (rFVIIa) in uncontrolled bleeding: a report by the Israeli Multidisciplinary rFVIIa Task Force. J Thromb Haemost 2005, 3:640-648.

14. Lynn M, Jeroukhimov I, Klein Y, Martinowitz U: Updates in the management of severe coagulopathy in trauma patients. Intensive Care Med 2002, 28(Suppl 2):24I-247.

15. Eikelboom JW, Bird R, Blythe D, Coyle L, Gan E, Harvey M, Isbister J, Leahy M, Mcllroy D, Rahimpanah F, Ramanthan S, Strasser S, Ward C, Watts A, Towler S, Yi Q: Recombinant activated factor VII for the treatment of life-threating haemorrhage. Blood Coagul Fibrinolysis 2003, 14:713-717.
Publish with Bio Med Central and every scientist can read your work free of charge

"BioMed Central will be the most significant development for disseminating the results of biomedical research in our lifetime. "

Sir Paul Nurse, Cancer Research UK

Your research papers will be:

- available free of charge to the entire biomedical community

- peer reviewed and published immediately upon acceptance

- cited in PubMed and archived on PubMed Central

- yours - you keep the copyright
BioMedcentral 